\title{
Implementing an Automated Road Maintenance Machine (ARMM): Lessons from the Field
}

\author{
Young-Suk Kim", Research Scientist, The University of Texas at Austin \\ Carl T. Haas, Associate Professor, The University of Texas at Austin \\ Ken Boehme, Senior Engineer, Texas Department of Transportation \\ Yong-Kwon Cho, Graduate Research Assistant, The University of Texas at Austin
}

\begin{abstract}
Crack sealing, a routine and necessary part of pavement maintenance, is a dangerous, costly, and labor-intensive operation. Within North America, about $\$ 200$ million is spent annually on crack sealing, with the Texas Department of Transportation (TxDOT) spending about $\$ 7$ million annually (labor alone accounts for over 50 percent of these costs). Prompted by concerns of safety and cost, the University of Texas at Austin, in cooperation with TxDOT and the Federal Highway Administration has developed a unique computerguided Automated Road Maintenance Machine for pavement crack sealing. Successful field tests have been undertaken in several TxDOT districts. This paper first describes the ARMM's field implementation and its productivity analysis results. The paper then discusses current research efforts, and improvements and modifications suggested though the technology evaluation during the field trials. The ARMM's future implementation and work plans are also presented in this paper.
\end{abstract}

\section{Background and Significance of Work}

Crack sealing, a maintenance operation undertaken by all state departments of transportation, is dangerous, costly, and laborintensive. In pursuing these operations, agencies must contend not only with the substantial personnel turnover and training problems associated with crack sealing, but also with the traffic disruptions that crack sealing operations typically generate. Automating pavement crack sealing can reduce labor and road user costs, improve work quality, and decrease worker exposure to roadway hazards.

Approximately $\$ 200,000,000$ is spent annually on crack sealing in North America. About $25 \%$ is privately contracted; labor costs average between $50 \%$ and $60 \%$ of total crack sealing costs. It is estimated that the ARMM would have a purchase cost of approximately $\$ 125,000$, a useful life of 5 years, $\$ 10,000$ annual maintenance costs, and $\$ 100,000$ in annual cost savings by eliminating three laborers. A very high rate of return (ROR) results.

According to the most recent economic analysis [3], if ARMMs were implemented throughout Texas, the direct savings are estimated to be $\$ 2.43$ million for TxDOT (at 4\% MARR) and \$2.64 million for the private contractors (at 20\% MARR) over a 6 year planning horizon. The user-cost savings are estimated using the widely accepted QUEWZ-E $[8,9]$ model to be $\$ 11.0$ million for the 5196 kilometers of the interstate highways in Texas. Total user-cost savings would be much higher since the savings on urban freeways and streets, farm-tomarket roads, and secondary roads are not included in this \$11 million estimate. Over a 30 year planning horizon and from a national perspective, the net present worth of automated crack sealing could be in the hundreds of millions of dollars.

A man-machine balanced Automated Road Maintenance Machine (ARMM) for automatically sealing pavement cracks has been developed, tested, and successfully demonstrated by the University of Texas at Austin, in cooperation with TxDOT, the FHWA, and Crafco, Inc. (Fig. 1). The previous crack sealing prototype systems (CMU Laboratory Prototype [1], CMU-UT Field Prototype [2], CalDavis Field Prototype [10], UT Field Prototype [3]) were fully autonomous but slow in field operation and impractical $[5,6]$. The ARMM uses an xy-manipulator with a rotating turret to blow, seal, and squeegee cracks in one pass, thus greatly improving productivity of the system. While the manipulator is moving within its work area, its frame is stationary. Sealing cracks in one work area and then moving to the next work area is

'Correspond to youngsuk@mail.utexas.edu or (512) 471-0110 
considered one work cycle. To control the ARMM through a work cycle, five steps are required including: (1) image acquisition, (2)

manual crack mapping and representation, (3) automated line snapping and manual line editing,

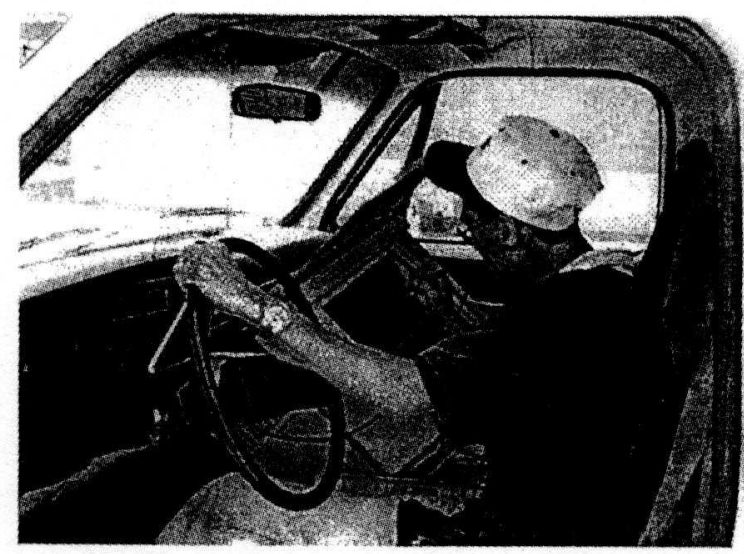

(a) Crack Tracing by the System Operator

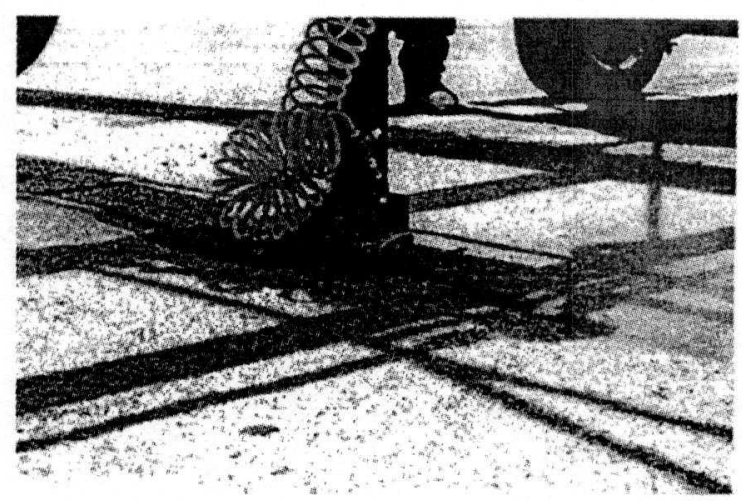

(c) Blowing, Sealing, Squeegeeing Cracks
(4) automated path planning, and (5) manipulator and end effector control.

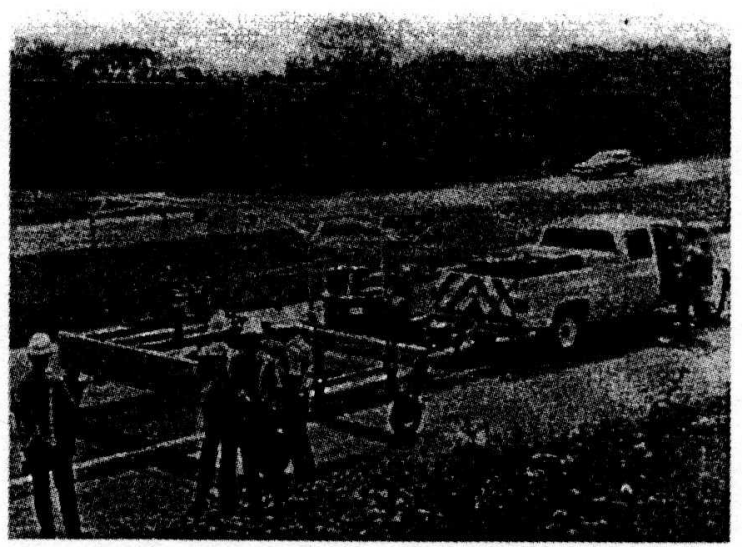

(b) The ARMM in the Field

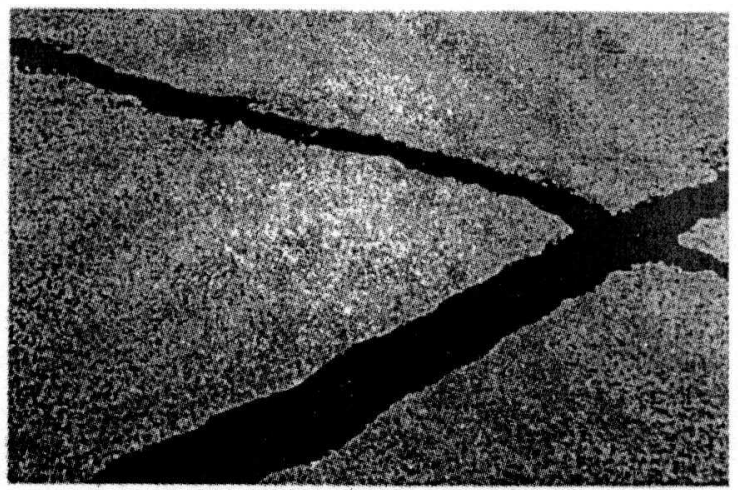

(d) A Resultant Seal by the ARMM

Fig. 1. Automated Road Maintenance Machine and Its Field Trial

\section{Field Implementation of the ARMM}

In 1997 and 1998, field trials were conducted at six locations around the state of Texas with encouraging results. Evaluations were submitted by maintenance personnel, vendors, and key administrators. Productivity analyses also indicated that the economics of the current prototype are beginning to be competitive with conventional methods, while only minor changes are required to significantly improve the machine's advantages. Numerous additional benefits are also associated with the crack sealing technology:

- Greater accuracy than manual methods has been observed.

- Less wastage of materials is expected, because of the application method and because video documentation of all operations is possible. Reduced waste of rubberized asphalt sealant material is an environmental benefit.

- Since the ARMM can work at night, safety and reduced congestion benefits to vehicular traffic are also expected.

- Safety is improved significantly by removing three laborers from hazardous roadwork. Interference with traffic should be minimized as well.

- Measurement of the exact total length of cracks filled can be made automatically. Images of work performed can also be automatically recorded

- Functionality of the machine can be extended with minor modifications to routing, cutting for loop detectors, refinishing, sensor manipulation, installation of specialized 
pavement markings, joint sealing, pothole filling, and other tasks.

During the field trials, evaluation of the crack sealing technology was based on field trial experiences, observations by maintenance personnel, key vendor input, and detailed productivity analysis. Key technical advances that have already been implemented include: (1) merged, real time, dual camera viewing, (2) simplified graphical control buttons, and variable speeds for cracks of variable widths (Fig. 2), (3) computer controlled electronic switch for the sealant wand, (4) motion control modifications, and (5) larger motors.
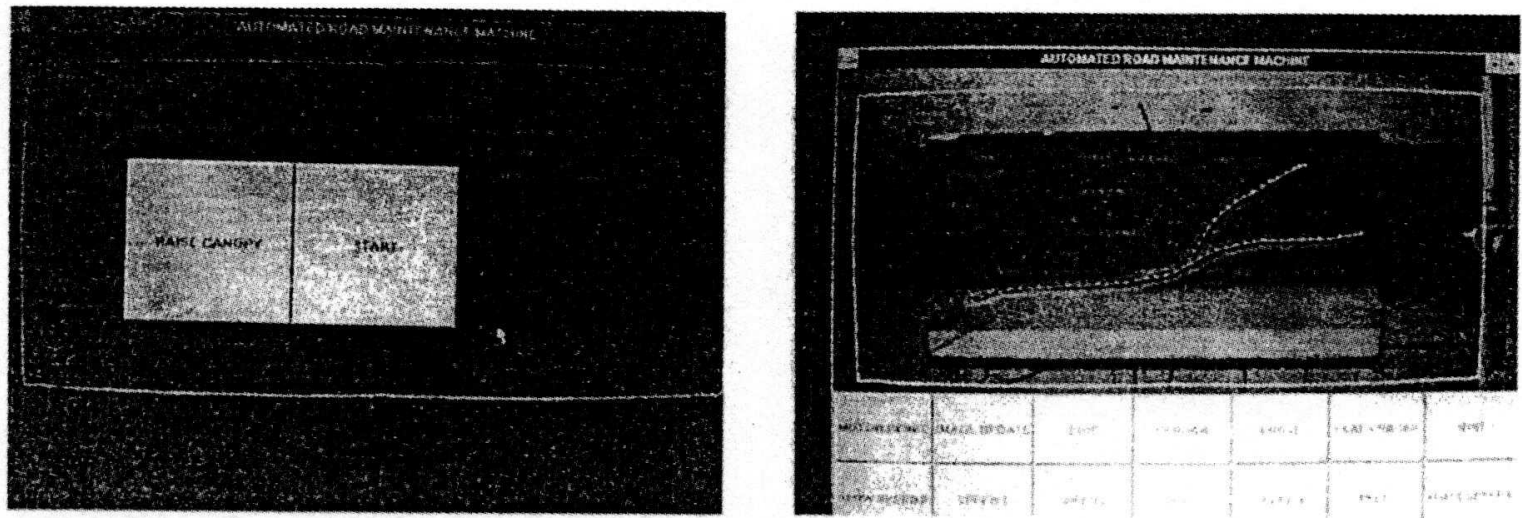

Fig. 2 Graphical User Interface of the ARMM's Vision Software

\section{Anticipated Productivity Analysis}

The main objectives of the productivity study were to determine if the ARMM can meet and exceed the productivity of standard crack sealing crews, and to rate the overall performance of the ARMM according to the severity and types of cracking. A mathematical model [4; Table 1] which predicts the productivity of the ARMM was developed as a means of rating the performance of the ARMM, and for estimating ARMM performance for future work. In the equation, the tasks associated with the ARMM's operation were divided into five major components (Table 2) to rate its overall performance. Data for the productivity analysis were collected from a series of field trials that were conducted. Distress types of pavement sections for the productivity study were divided into four major categories including: (1) Longitudinal cracking, (2) Transverse cracking, (3) Block cracking, and (4) Joints. Alligator cracking was not sampled because other surface crack maintenance options such as 'patches' or 'overlays' are preferred to repair the alligator cracking, instead of the 'routing and sealing' method.

Table 1 Productivity Model for Performance Evaluation of the ARMM

\begin{tabular}{l}
\hline Productivity Model \\
\hline Productivity of the ARMM (lane-kilometer/hour) = Total length of sealed pavement / [Time to mobilize + \\
Total time to trace, line snap, and path plan + Total time to blow, seal, and squeegee + Total time to move the \\
ARMM + Time to demobilize]
\end{tabular}


Table 2 Five Components Classified for Productivity Study of the ARMM

\begin{tabular}{|c|c|}
\hline Components & Times Measured \\
\hline 1. Mobilization & $\begin{array}{l}\text { - Start and charge the melter } \\
\text { - Unload the ARMM from the melter } \\
\text { - Hook up the ARMM to the melter } \\
\text { - } \text { Hook up the cables and hoses } \\
\text { - Turn on the computer } \\
\text { - Start the generator and air compressor }\end{array}$ \\
\hline $\begin{array}{l}\text { 2. Crack Detection, Manual Mapping, Line } \\
\text { Snapping, and Manual Line Editing }\end{array}$ & $\begin{array}{l}\text { - } \\
\text { - } \quad \text { Trace cracks to be sealed } \\
\text { - Start line snapping, do manual line editing (if } \\
\text { necessary) and do path planning }\end{array}$ \\
\hline 3. Crack Sealing & - Blow, seal, and squeegee cracks in one pass \\
\hline 4. Move to the Next Workspace & $\begin{array}{l}\text { - } \begin{array}{l}\text { Drive the tow vehicle to find cracks } \\
\text { Stop the tow vehicle if there are cracks on the } \\
\text { roadway }\end{array}\end{array}$ \\
\hline 5. Demobilization & $\begin{array}{l}\text { - Turn off the computer, melter, generator, air } \\
\text { compressor, and cables and hoses } \\
\text { - Unhook the ARMM from the melter } \\
\text { - Lower the canopy } \\
\text { - Load the ARMM on the trailer }\end{array}$ \\
\hline
\end{tabular}

The most recent productivity analysis result $[4$, 5] indicated that currently, the ARMM is competitive with conventional methods [5] (Table $3)$, but has greater accuracy, less waste, and the other associated benefits described earlier.
Considering the natural variability of road conditions, and the limited data collected to date, these results should only be considered accurate to within $25 \%$.

Table 3 Productivity Comparison of

\begin{tabular}{c|c}
\hline \multicolumn{2}{c}{ Overall Daily Productivity } \\
\hline ARMM & Conventional Method \\
\hline 3.1 lane-kilometers/day & 3.2 lane-kilometers/day [7] \\
\hline
\end{tabular}

However, this productivity rate of the ARMM should easily outperform the conventional methods in the near future, by employing several improvements listed in Table 4 . Those would include: (1) use of faster processor, (2) fabrication of lighter x-y manipulator, (3) use of faster motors, (4) ergonomic design of tow vehicle's cab, and (5) adding lights for night time operation. For example, the ARMM with the ability to work at night with the mounting of lights on its canopy would almost double the current daily production rate. When regarding these elements, the achievable productivity rate of the ARMM should be greater than that presented above, thus making automated crack and joint sealing more favorable. Also, in the current prototype system, the crews are spending much time on mobilizing (20 minutes) and demobilizing (15 minutes) the ARMM [5]. In the long run, the ARMM would be built as a single unit. In this case, times for mobilization and demobilization will be significantly reduced. This will also improve the overall productivity of the ARMM. Using the productivity model it is estimated that these improvements would result in a production rate of 4.5 lane-kilometer/day; [5] at no added cost.

\section{Current Research Efforts and Future Plan}

Current research efforts are focused on field trials and improvements of the machine. Since the system performs well in its current configuration, demonstrations can be interspersed throughout the year with work on improvements and field trials. In 1999, the field trials with a full-scale crack sealer will be conducted in ten states around the country (AZ, CA, UA, CO, WY, ND, OK, MO, PA, TX; Fig. 3). The schedule for the ARMM's field demonstrations is being finalized. The ASCE, 
NCHRP, AASHTO, and WASHTO meetings, along with state highway departments' research meetings, and various locations throughout the nation where a significant interest has been shown, would also be potential demonstration sites. Objectives of the field demonstrations will be to:

- gain additional field experience
- acquaint maintenance personnel around the country to the potential of the automated crack sealing technology

- collect additional productivity data

- acquire more feedback from maintenance personnel

- perform further proof testing the equipment under real working conditions

- acquire additional video footage

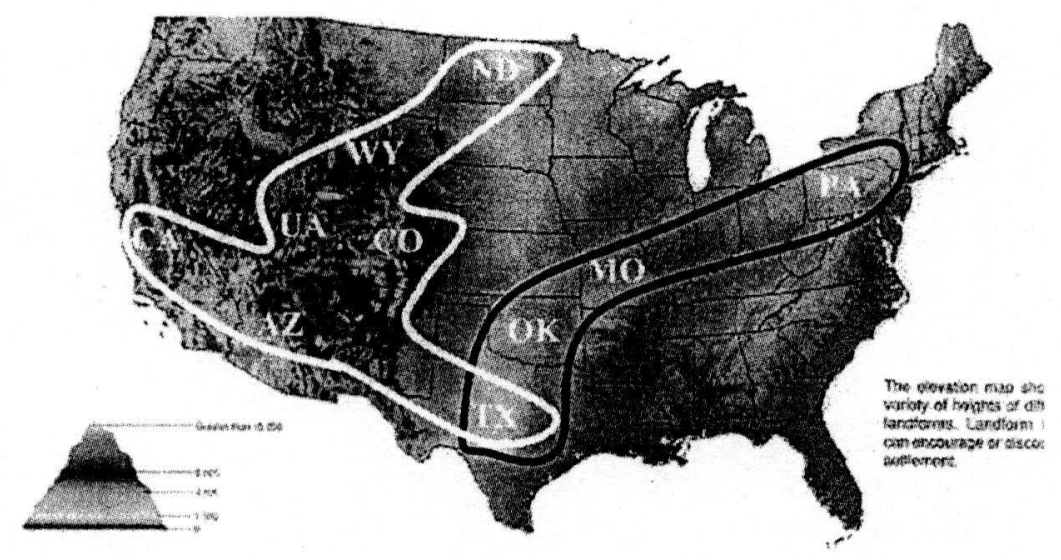

Fig. 3 The ARMM's Field Demonstration Schedule in 1999

Improvements based on the evaluations varied in terms of their anticipated benefit/cost ratios. The following improvements with high benefit cost ratios are being currently conducted at the Field Systems and Construction Automation Laboratory of the University of Texas at Austin.

Table 4 Suggested Improvement and Modifications

\begin{tabular}{l} 
Planned Improvements \\
- Replace current office 486 PC with industrial Pentium PC \\
- Use a spring loaded, U shaped squeegee \\
- Mevelop a retractable turret \\
- Modify bearings, gantry, and motors to triple end-effector (tool) speed \\
- Add better tinting, or mini-blinds to reduce glare on monitor \\
\hline
\end{tabular}

Ownership of the technology itself is public, since its development was government funded. The state of Texas has allocated funds for the acquisition of a commercial model in 1999. The bid specifications were developed based on performance criteria rather than prescriptive details, therefore it is expected that the technology will experience further refinement when it is commercialized.

Additional lessons learned from the field demonstrations included:
- Reactions vary widely.

- Proof testing in public is risky.

- Expeditions can be extreme.

- Impediments to technological innovation similar to those in construction.

\section{Conclusions and Recommendations}

Automating pavement crack sealing will improve productivity, and quality and have safety 
benefits by getting workers off the road. In the case of the ARMM, the reduction in crew size and the increase in productivity of the sealing process will translate directly into significant potential savings in costs. Recent field trials of the full scale crack sealer have indicated that automated pavement crack sealing is technically, economically, and financially feasible. The results of the ARMM's recent field trials conducted at six locations in the state of Texas were enough to support this conclusion. Demonstrating the ARMM around the country would accelerate transfer of the automated crack sealing technology. After gaining additional field experience, detailed design analysis of the ARMM in preparation of possible fabrication of future commercial models and quality analysis of the resultant seals will be conducted. Finally, it is anticipated that partial modifications of the algorithms and tools used in the ARMM would eventually have broader applications in automation of infrastructure maintenance. Applications areas would include: (1) pothole filling, (2) acquisition of as-built drawings, (3) tracking and modeling of deterioration or crack propagation, and (4) automated routing, message painting, and marker placement.

\section{References}

1. Haas, C., Hendrickson, C. (1990). "Computer Based Model of Pavement Surfaces," Transportation Research Record, Washington D.C., No. 1260, 91-98.

2. Haas, C., Hendrickson, C., McNeil, S., and Bullock, D. (1992). "A Field Prototype of a Robotic Pavement Crack Sealing System," Proc. of the $9^{\text {th }}$ International Symposium on Automation and Robotics in construction (ISARC), Tokyo, Japan, 313-322.

3. Haas, C. (1996). "Evolution of an Automated Crack Sealer: A Study in Construction Technology Development," Auto. in Constr. 4, Elsevier, 293-305.

4. Kim, Y., Husbands J., Haas, C., Greer, R., and Reagan A. (1997). "Productivity Model for Performance Evaluation of the UT Automated Road Maintenance Machine," Proc. of the $14^{\text {th }}$ International Symposium on Automation and Robotics in Construction, Pittsburgh, PA. June 8-11.

5. Kim, Y.S. (1997). "Man-Machine Balanced Control for Automation of Infrastructure Crack Sealing" Dissertation, Department of Civil Engineering, The University of Texas at Austin, Austin, Texas, December.

6. Kim, Y., Haas, C., and Greer, R. (1998). "Man-Machine Balanced Crack Sealing Process for the UT Automated Road
Maintenance Machine," accepted by the ASCE, $5^{\text {th }}$ International Conference on Applications of Advanced Technologies in Transportation Engineering, Newport Beach, C.A.

7. Malek, G.J. (1993). "Methods, Practices, and Productivity Study of Crack Sealing/Filling in Texas," Master's Thesis, Department of Civil Engineering, The University of Texas at Austin, Austin, Texas, May.

8. Memmot, J., and Dudek, C. (1982). "A Model to Calculate the Road User Costs at Work Zones," Research Report 292-1, Texas Transportation Institute, September.

9. Seshadri, P., Solminihac, H.E., and Harrison, R. (1993). "Modification of the QUEWZ Model to Estimate Fuel Costs and Tailpipe Emissions," Proc. 72 ${ }^{\text {nd }}$ Annual Meeting of Transportation Research Board, Washington D.C.

10. Velinsky, S.A. (1993). "Fabrication and Testing of an Automated Crack Sealing Machine," National Research Council, SHRP. H-659, Washington, D.C. 